\title{
Executive and attentional functions in chronic pain: Does performance decrease with increasing task load?
}

\author{
Joukje M Oosterman $\mathrm{PhD}^{1,2}$, Laura C Derksen $\mathrm{MSc}^{2}$, Albert JM van Wijck MD PhD ${ }^{3}$, \\ Roy PC Kessels $\mathrm{PhD}^{1,4}$, Dieuwke S Veldhuijzen $\mathrm{PhD}^{3}$
}

\begin{abstract}
JM Oosterman, LC Derksen, AJM van Wijck, RPC Kessels, DS Veldhuijzen. Executive and attentional functions in chronic pain: Does performance decrease with increasing task load? Pain Res Manage 2012;17(3):159-165.
\end{abstract}

BACKGROUND: Diminished executive function and attentional control has been reported in chronic pain patients. However, the precise pattern of impairment in these aspects of cognition in chronic pain remains unclear. Moreover, a decline in psychomotor speed could potentially influence executive and attentional control performance in pain patients.

OBJECTIVE: To examine different aspects of executive and attentional control in chronic pain together with the confounding role of psychomotor slowing.

METHODS: Neuropsychological tests of sustained attention, planning ability, inhibition and mental flexibility were administered to 34 participants with chronic pain and 32 control participants.

RESULTS: Compared with the controls, participants with chronic pain took longer to complete tests of sustained attention and mental flexibility, but did not perform worse on inhibition or planning tasks. The decreased performance on the mental flexibility task likely reflects a reduction in psychomotor speed. The pattern of performance on the sustained attention task reveals a specific decline in attention, indicated by a disproportionate decline in performance with an increase in task duration and by increased fluctuations in attention during task performance. No additional effect was noted of pain intensity, pain duration, pain catastrophizing, depressive symptoms, reduced sleep because of the pain or opioid use.

CONCLUSIONS: Executive and attention functions are not uniformly affected in chronic pain. At least part of the previously reported decline in executive function in this group may reflect psychomotor slowing. Overall, limited evidence was found that executive and attention performance is indeed lower in chronic pain. Therefore, it can be concluded that in chronic pain sustained attention performance is diminished while mental flexibility, planning and inhibition appear to be intact.

Key Words: Attention; Chronic pain; Executive function; Pain catastrophizing; Pain intensity; Psychomotor speed

\author{
La fonction exécutive et l'attention en cas de \\ douleur chronique : le rendement est-il \\ inversement proportionnel à la charge de travail ?
}

HISTORIQUE : Chez les patients atteints de douleur chronique, on remarque une diminution de la fonction exécutive et du contrôle de l'attention. Toutefois, les motifs d'atteinte précis de ces aspects de la cognition ne sont pas clairs en cas de douleur chronique. De plus, un ralentissement psychomoteur pourrait influer sur le rendement exécutif et le contrôle de l'attention chez ces patients.

OBJECTIF : Examiner divers aspects de la fonction exécutive et du contrôle de l'attention en cas de douleur chronique de même que le rôle confusionnel du ralentissement psychomoteur.

MÉTHODOLOGIE : Les chercheurs ont fait faire des tests neuropsychologiques d'attention soutenue, de planification, de capacités, d'inhibition et de flexibilité mentale à 34 participants ayant des douleurs chroniques et à 32 sujets témoins.

RÉSULTATS : Par rapport aux sujets témoins, les participants atteints de douleur chronique prenaient plus de temps pour effectuer les tests d'attention soutenue et de flexibilité mentale, mais n'obtenaient pas de moins bons résultats pour ce qui est des tâches d'inhibition ou de planification. Le moins bon rendement en matière de flexibilité mentale reflète probablement une diminution de la vitesse psychomotrice. Le motif de rendement à la tâche d'attention soutenue révèle une diminution précise de l'attention, indiquée par une diminution disproportionnée du rendement, une augmentation de la durée de la tâche et des fluctuations plus marquées de l'attention pendant l'exécution de la tâche. Les chercheurs n'ont remarqué aucun effet additionnel sur l'intensité de la douleur, la durée de la douleur, la catastrophisation de la douleur, les symptômes dépressifs et la réduction du sommeil à cause de la douleur ou de la prise d'opiacés. CONCLUSIONS : La fonction exécutive et l'attention ne sont pas uniformément touchées par la douleur chronique. Au moins une partie de la diminution de la fonction exécutive signalée antérieurement dans ce groupe pourrait refléter un ralentissement psychomoteur. Dans l'ensemble, les données sont limitées pour déterminer que le rendement exécutif et le contrôle de l'attention diminuent réellement en cas de douleur chronique. Par conséquent, on peut conclure qu'en cas de douleur chronique, l'attention soutenue diminue, tandis que la flexibilité mentale, la planification et l'inhibition semblent demeurer intactes.

$\mathrm{T}$ he influence of pain on neuropsychological test performance has been widely acknowledged $(1,2)$. Many studies have reported that executive and attentional functions are affected in chronic pain patients, presumably as a result of competing attentional demands of chronic pain (2-5). Due to this interruptive nature of pain, it is presumed that less cognitive resources are available for other processes, including cognitive function. Because multiple functions are commonly attributed to the concepts of executive and attentional control (6), it is one of the most heterogeneous and least well understood cognitive domains to date. Furthermore, it is difficult to segregate concepts of attention and executive functions at a conceptual level. For example, attention encompasses multiple functions including sustained, divided and selective (or focused) attention $(6,7)$, but a strong

overlap exists between these attentional functions and those that are commonly regarded as executive control. This is nicely illustrated by tests such as the Trail Making Test (TMT) and the Stroop Colour Word task. The TMT part B (8) requires participants to switch between different stimuli and to keep track of previously encountered items. Hence, this test requires divided attention for successful performance but is commonly regarded as a test of mental flexibility (9). The Stroop Colour Word test (10) requires the inhibition of one type of stimulus while responding to another stimulus. This test is, therefore, commonly regarded as a measure of cognitive inhibition, but it also requires the ability to focus attention on one aspect of the task while suppressing another aspect, ie, selective attention (6). For the sake of clarity, when we refer to a task in the present article, we will

${ }^{1}$ Radboud University Nijmegen, Donders Institute for Brain, Cognition and Behaviour, Nijmegen; ${ }^{2}$ Experimental Psychology, Helmholtz Institute, Utrecht University; ${ }^{3}$ University Medical Center Utrecht, Rudolf Magnus Institute of Neuroscience, Division of Anesthesiology, Intensive Care and Emergency Medicine, Pain Clinic, Utrecht; ${ }^{4}$ Departments of Medical Psychology and Geriatric Medicine, Radboud University Nijmegen Medical Centre, Nijmegen, The Netherlands

Correspondence: Dr Joukje M Oosterman, Radboud University Nijmegen, Donders Institute for Brain, Cognition and Behaviour, Montessorilaan 3 , 6500 HE Nijmegen, The Netherlands. Telephone 31-24-3611951, fax 31-24-3616066, e-mail j.oosterman@donders.ru.nl 
describe it in terms of the cognitive functions that are most commonly used in the research literature, such as inhibition for the Stroop task and mental flexibility for the TMT.

The studies to date reveal conflicting findings regarding the precise effect of chronic pain on these specific executive and attention functions. Some studies failed to find decreased performance of chronic pain patients compared with controls on tasks of inhibition $(11,12)$, mental flexibility (12-14) and letter fluency (12). In contrast, other studies reported on significant associations between chronic pain and inhibition (4), mental flexibility $(15,16)$ and sustained attention $(5,17)$. The precise pattern of performance on tasks of executive and attention tasks in chronic pain patients thus remains unclear.

A crucial factor that should be considered when examining executive and attentional task performance in chronic pain patients is whether this reflects a specific deficit or a decline in more basic cognitive abilities. More specifically, executive function and attention performance may be particularly vulnerable to a reduction in psychomotor speed (6), with psychomotor slowing being a consistent finding in chronic pain patients (18). This is an important consideration because frequently used tests to assess executive function and attention, such as the Stroop Colour Word test and the TMT, are strongly dependent on psychomotor speed performance (19-22). A decline in executive or attentional performance can therefore only be revealed when an increase in task demands substantially affects performance (3), with an effect that extends beyond a potential reduction in basic cognitive abilities such as psychomotor speed. Some studies attempted to adjust for reductions in these abilities by calculating difference scores, for example, by subtracting the completion time of different parts of the TMT. However, it was recently demonstrated that psychomotor speed still significantly contributes to performance on the TMT difference score (21). Interestingly, a study that adequately controlled for reductions in basic cognitive abilities by calculating the interference score of the Stroop Colour Word task did not find an effect of chronic pain on task performance (12). These findings imply that a decrease in executive and attentional task performance may at least be partly attributable to a decline in psychomotor speed. In addition, factors such as pain catastrophizing and a reduction in sleep quality and opioid use may all influence cognitive functioning (1), and could therefore potentially account for the heterogeneous findings regarding attention and executive function in chronic pain.

The aim of the present study was to examine the extent to which chronic pain affects psychomotor speed, and whether the effects of chronic pain on executive and attention functions reflect a decline that extends beyond a reduction in this psychomotor slowing. In the present study, a repeated measures ANOVA was employed to allow for examining disproportional diminished task performance in participants with chronic pain with increasing task demands or duration (3). As such, it could be determined whether group differences on tasks represented specific executive and attention impairments. In line with previous findings (18), chronic pain participants were expected to perform more slowly on the neuropsychological tests. In addition, specific lower performance on the attention and executive function tests was anticipated $(4,5,16,17)$.

\section{Participants}

A total of 34 participants with chronic pain were involved in the study. Participants with chronic pain were included in cooperation with the Pain Clinic at the University Medical Centre Utrecht, the Netherlands $(n=7)$, or were participants of a previous (unrelated) study $(n=9)$ or were recruited through advertisements (ie, pain internet sites and oral advertising $[n=18])$. All participants reported persistent pain for $>6$ months (mean duration 11.7 years, median 6.5 years, range one to 50 years). Chronic pain conditions could be categorized as visceral pain $(n=8)$, musculoskeletal pain $(n=21)$, neuropathic pain $(n=3)$ and other $(n=5)$. Three participants suffered from more than one chronic pain condition. The majority of participants with chronic pain used pain medication: 17 participants used acetaminophen (paracetamol), 13 used a nonsteroidal anti-inflammatory drug (ie, diclofenac, diclofenac plus misoprostol, naproxen, ibuprofen), 11 were receiving opioids (ie, tramadol, fentanyl, acetaminophen plus codeine, acetaminophen plus tramadol), one used a tricyclic antidepressant (amitriptyline) and one used acetaminophen combined with caffeine. Four participants did not use any analgesic medication. Current pain intensity was rated using a $10 \mathrm{~cm}$ visual analogue scale of the Dutch translation of the McGill Pain Questionnaire (23). Thirty-two ageand IQ-matched control participants were also recruited. All participants reported to be free of a history of neurodegenerative disorders (eg, dementia), stroke, major depressive disorder, and alcohol or other substance abuse.

Premorbid IQ was estimated with the Dutch version of the National Adult Reading Test (24). Additionally, the Mini Mental State Examination (25) was administered to exclude participants with possible severe cognitive decline (defined as a score $<24$ ). No participants were excluded on this basis. The characteristics of the participants are presented in Table 1. Approval for the study was obtained from the Medical Ethics Committee of the University Medical Centre Utrecht. All participants signed an informed consent form.

\section{Neuropsychological tests}

All participants completed four tests to assess executive function and attention. First, the Stroop Colour Word test (10) was assessed to measure inhibition. This test consists of three cards, namely the Word (W) card, the Colour (C) card, and Colour/Word (C/W) card. The W card consists of 10 rows with 10 colour names in each row which are all printed in black ink. The participant is required to read aloud these colour names as fast as possible. For the $\mathrm{C}$ card, 10 rows are presented containing 10 coloured blocks per row, which the participant is required to name as fast as possible. On the $\mathrm{C} / \mathrm{W}$ card, colour names are printed in an incongruent colour, and the participant is required to name the colours in which the words are printed as fast as possible. The time needed to finish each of the cards was measured. Performance on the first two cards reflects basic cognitive abilities such as psychomotor speed and reading ability, whereas the third card specifically addresses inhibition. To establish diminished inhibition performance in chronic pain, a disproportional decline in performance should be present on the $\mathrm{C} / \mathrm{W}$ card, ie, group differences should be more pronounced for the $\mathrm{C} / \mathrm{W}$ card than for the $\mathrm{W}$ and $\mathrm{C}$ cards.

Second, the Trail Making Test (8) is a visual search task, measuring mental flexibility. The TMT part A consists of 25 encircled numbers that are randomly distributed on a sheet of paper. The participant is required to connect these numbers sequentially. On the TMT part B, both numbers and letters are distributed. This time, the participant is instructed to alternate between the numbers and letters (ie, 1, A, 2, B, 3, etc). Completion times of part A and B were measured. Part A is considered to measure basic abilities such as motor speed and visual search (19), whereas part B examines mental flexibility. Again, to establish whether performance on part B extends beyond a mere reduction in basic cognitive abilities in chronic pain, a disproportional decline in TMT part B performance in the chronic pain group should be present, which extends beyond group differences in TMT part A performance.

Third, the Bourdon-Vos test (26) was administered to measure sustained attention. This test consists of 33 lines containing groups of three, four or five dots presented on a sheet of paper. Participants are instructed to cross out the groups with four dots as fast and accurately as possible. Completion time and the number of omissions (27) are recorded for each line. When only examining the total score (eg, total completion time), no information about the ability to sustain attention can be obtained. Here, a longer completion time might only indicate basic cognitive slowing per se, without an impaired ability to sustain attention over time. Therefore, the study calculated the average time to complete a line, and the average number of omissions for each line separately for the first one-half of the test (lines 1-17) and 
the second one-half of the test (lines 18-33). A specific decline in sustained attention should be reflected by increased slowing, as well as an increased number of omissions, on the second half compared with the first half of this test in the chronic pain group. In addition, the variability in performance on this task was calculated by examining the reaction time and omission scores per row for all 33 rows (28). Lower sustained attention performance was indicated by an increased variability, reflecting an increase in fluctuations in attention, in the completion time and the number of omissions over the different lines of the task.

Finally, the Zoo Map test of the Behavioural Assessment of the Dysexecutive Syndrome (29) was used to assess planning ability. This test consists of an unstructured first part and a structured second part. In the first part, participants are instructed to plan their route through a map of the zoo, visiting a selection of places while bypassing others. While planning the route, participants also need to obey to some rules. The second part consists of the same map with the same places that have to be visited, only this time instructions are provided about the precise order of visits. This second part, therefore, strongly reduces the involvement of planning functions. For both cards, the maximum score ranged between 0 and 8 . Points were deducted if an error was made (ie, using a path more than once, deviations from the path, failure to make a continuous line and inappropriate places visited). Both planning and completion time were measured. A specific planning problem in chronic pain means that performance (raw score, planning or completion time) on the first unstructured card should be disproportionately affected compared to the second, more structured, card.

\section{Potential confounders}

Pain catastrophizing was measured with the Pain Catastrophizing Scale (PCS) (30-32), because this may be an important mediator of the cognitive impairments observed in chronic pain patients $(33,34)$. The Geriatric Depression Scale (GDS) (35) was administered to measure depressive symptoms, which is a reliable indicator of depressive symptoms in both the elderly population and in younger adults $(36,37)$. In the chronic pain group, the number of hours lying awake because of the pain was also measured with the McGill Pain Questionnaire. Finally, the influence of pain duration on performance was examined, because an increase in the duration of pain has been associated with an increase in brain grey and white matter changes $(38,39)$, which likely affect cognitive function.

\section{Procedure}

Participants were contacted through the pain clinic, internet sites, oral advertising or were participants of a previous study. After informed consent was obtained, participants completed a single test session. Tests and questionnaires were always administered in the same order: participants first completed the questionnaires and then the neuropsychological tests (all in a fixed order). A total session lasted approximately $1 \mathrm{~h}$ to $1.5 \mathrm{~h}$.

\section{Statistical analyses}

Logarithmic transformation was applied to the TMT part A and B completion time measures, and inverse normalizing transformation (40) to the Bourdon-Vos omissions (both first half and second half); to the attention fluctuations reflected by the variability in completion time and omission score of each line of the Bourdon-Vos; and to the Zoo Map raw score, the planning and the completion time measures.

A $2 \times 3$ mixed-design ANOVA was used for the Stroop Colour Word test with group (control versus chronic pain participants) as the between-subject factor and completion time of the cards (W, C and $\mathrm{C} / \mathrm{W})$ as the within-subject factor. A $2 \times 2$ mixed-design ANOVA was performed for the TMT test, with test version (TMT-A, TMT-B) as the within-subject factor and group as the between-subject factor. A similar design was employed twice for the Bourdon-Vos test with the completion time (first half, second half) and the number of omissions (first half, second half) as separate within-subject variables and group as a between-subject factor. The variability in completion time and omissions of the different lines was analysed using a multivariate ANOVA (MANOVA) with group (control versus chronic pain) as the independent variable and the completion time and omission variance as dependent variables. A $2 \times 2$ mixed-design was also used for the Zoo Map test, where the analyses were run separately for the raw score, the planning time and the completion time of both cards. For all analyses the study focused on the main effect of group and on the interaction between group and the test variables. For all these analyses the sphericity assumption (Mauchly's test), the homoscedasticity assumption (Box's M test) and the homogeneity assumption (Levene's test) were met.

$\mathrm{T}$ tests were employed to test for group differences in IQ, age and pain catastrophizing. Group differences in depressive symptoms were tested with the Mann-Whitney $U$ test because these scores were not normally distributed. Sex distribution was examined with a Pearson $\chi^{2}$ test. For these and the above-mentioned tests, the level of significance was set at $\mathrm{P}<0.05$.

Pearson correlations were calculated in the chronic pain group between current pain intensity, pain duration, pain catastrophizing, depressive symptoms and the hours lying awake on the previous night because of the pain on the one hand and the cognitive tasks on the other. This analysis was performed to examine whether an increase in pain severity, duration, depressive symptoms, catastrophizing or a reduction in sleep quality was related to a more pronounced decline in task performance. Mann-Whitney $U$ tests were performed to examine potential group differences in cognitive task performance between chronic pain participants who did and did not use opioids. To reduce the risk of type I error due to multiple testing, the level of significance for the correlational tests was set at $\mathrm{P}<0.01$.

Finally, insufficient effort has been reported in chronic pain patients, particularly in those seeking litigation $(41,42)$. These factors may result in decreased neuropsychological test performance $(43,44)$. To address this possibility, for each patient the present study compared their performance on each test to normative data and specifically examined the number of participants who performed in the impaired range (2 SD or more below average).

\section{RESULTS}

The chronic pain and healthy control groups did not differ significantly in age $(\mathrm{t}[64]=0.75, \mathrm{P}=0.46)$, sex $\left(\chi^{2}[1]=2.30, \mathrm{P}=0.13\right)$ and $\mathrm{IQ}$ $(\mathrm{t}[64]=1.88[\mathrm{P}=0.065])$ (Table 1). Participants with chronic pain had in general higher PCS scores compared with the controls $(\mathrm{t}[64]=-2.9$, $\mathrm{P}<0.01)$. Depressive symptoms were significantly increased in the chronic pain group $(\mathrm{Z}=-4.58[\mathrm{P}<0.001])$. This variable (normalized using Blom transformation) was therefore used as a covariate in the subsequent repeated measures analyses. The performance of both groups on all tasks is presented in Table 2.

\section{Inhibition}

No significant main effect for group $\left(F[1,63]=0.25, P=0.62, \eta^{2}=0.00\right)$ or a significant interaction between group and task performance $(F[2$, $126]=0.71, P=0.49, \eta 2=0.00$ ) was found on the completion time of the Stroop Colour Word test.

\section{Mental flexibility}

A significant main effect of group was observed for the TMT (F[1, $\left.63]=7.74, P<0.01, \eta^{2}=0.11\right)$. Overall, participants with chronic pain took longer to complete the TMT part A and part B than the controls. However, the interaction between group and task performance was not significant $\left(F[1,63]=0.30, P=0.59, \eta^{2}=0.00\right)$, implying that an increase in task demands (part B compared with part A) affected performance in the chronic pain and the control group to a similar extent.

\section{Sustained attention}

A significant main effect of group $\left(F[1,63]=5.28, P<0.05, \eta^{2}=0.07\right)$ was found for the completion time of the Bourdon-Vos test, indicating that, overall, the chronic pain group took longer to complete this test. The interaction between group and task performance was not 
TABLE 1

Characteristics of the participants

\begin{tabular}{lcc}
\hline & Controls & Chronic pain patients \\
\hline $\mathrm{n}$ & 32 & 34 \\
Age, years & $55.4 \pm 22.0$ & $51.5 \pm 20.4$ \\
Sex, male/female, $\mathrm{n} / \mathrm{n}$ & $12 / 20$ & $7 / 27$ \\
$\mathrm{IQ}$ & $105.4 \pm 8.1$ & $101.0 \pm 10.6$ \\
$\mathrm{GDS}$ & $3.5 \pm 3.6$ & $9.2 \pm 5.9^{\star}$ \\
$\mathrm{PCS}$ & $13.6 \pm 8.2$ & $20.4 \pm 10.5^{\star}$ \\
Current pain, $\mathrm{mm}$ & - & $34.9 \pm 23.3$ \\
\hline
\end{tabular}

Data for age, IQ, Geriatric Depression Scale (GDS), Pain Catastrophizing

Scale $(P C S)$ and pain intensity scores are presented as mean $\pm S D$.

Frequencies are reported for sex distribution. *Significant group difference at $P<0.05$

TABLE 2

Executive and attention task performance in the chronic pain and control groups

\begin{tabular}{|c|c|c|}
\hline & Control & Chronic pain \\
\hline \multicolumn{3}{|l|}{ Stroop } \\
\hline W card (time) & $49.0 \pm 10.0$ & $47.4 \pm 8.3$ \\
\hline C card (time) & $59.2 \pm 9.2$ & $61.8 \pm 10.2$ \\
\hline C/W card (time) & $97.7 \pm 24.6$ & $99.4 \pm 21.7$ \\
\hline \multicolumn{3}{|l|}{ TMT } \\
\hline Part A (time) & $31.7 \pm 9.9$ & $40.3 \pm 15.5^{\star}$ \\
\hline Part B (time) & $76.9 \pm 27.8$ & $98.0 \pm 56.8$ \\
\hline \multicolumn{3}{|l|}{ Bourdon-Vos } \\
\hline Total time & $409.2 \pm 85.7$ & $432.8 \pm 95.3$ \\
\hline Time first half & $12.3 \pm 2.6$ & $13.0 \pm 2.9$ \\
\hline Time second half & $12.5 \pm 2.6$ & $13.3 \pm 2.9$ \\
\hline Completion time variance & $1.8 \pm 1.6$ & $2.9 \pm 3.1^{*}$ \\
\hline Total omissions & $10.1 \pm 7.9$ & $14.9 \pm 15.7$ \\
\hline Omissions first half & $0.32 \pm 0.26$ & $0.41 \pm 0.56$ \\
\hline Omissions second half & $0.29 \pm 0.26$ & $0.49 \pm 0.43^{*}$ \\
\hline Omissions variance & $0.32 \pm 0.29$ & $0.64 \pm 0.87$ \\
\hline \multicolumn{3}{|l|}{ Zoo Map } \\
\hline Card 1 raw score & $4.1 \pm 3.1$ & $4.6 \pm 3.3$ \\
\hline Card 1 planning time & $59.5 \pm 37.8$ & $74.7 \pm 68.2$ \\
\hline Card 1 completion time & $105.7 \pm 67.7$ & $75.4 \pm 61.8$ \\
\hline Card 2 raw score & $7.7 \pm 1.0$ & $7.7 \pm 1.2$ \\
\hline Card 2 planning time & $9.6 \pm 18.1$ & $7.9 \pm 16.6$ \\
\hline Card 2 completion time & $40.2 \pm 17.3$ & $45.6 \pm 30.0$ \\
\hline
\end{tabular}

Scores presented as mean $\pm S D$. The Bourdon first and second half indices represent the average performance (completion time or omissions) per line (of a total of 33 lines). The variance indices represent the variance in either completion time or omissions across the 33 lines of the Bourdon-Vos test. *Significant group differences at $P<0.05$ as indicated with $\mathrm{t}$ tests (using normalized scores for the TMT variables, the Bourdon-Vos total omissions and variance in completion time and omissions, as well as all Zoo Map variables). C Colour; C/W Colour/word; W Word; TMT Trail Making Test

significant $\left(F[1,63]=0.08, P=0.78, \eta^{2}=0.00\right)$. Analyses of the omissions on this test revealed no significant main effect of group $(F[1,63]=2.51$, $\left.\mathrm{P}=0.12, \eta^{2}=0.04\right)$, but it did reveal a significant interaction effect between group and the number of omissions $(\mathrm{F}[1,63]=5.51, \mathrm{P}<0.05$, $\left.\eta^{2}=0.08\right)$. While the control group performed slightly better with regard to the number of omissions in the second half compared with the first half of this test $(\mathrm{t}[31]=1.79, \mathrm{P}=0.08)$, a marginally significant increase in the number of omissions in the second part of this test was found for participants with chronic pain $(\mathrm{t}[33]=-1.93, \mathrm{P}=0.06)$. Finally, a significant effect was found for fluctuations in attention as indicated by the variability in the completion time and omission scores $\left(\mathrm{F}[2,62]=3.15, \mathrm{P}<0.05, \eta^{2}=0.09\right)$. Chronic pain patients were more variable with regard to the completion time $(F[1,63]=5.67$,
TABLE 3

Prevalence of impaired neuropsychological task performance in the control and chronic pain groups

\begin{tabular}{lccc}
\hline & Controls $(\mathbf{n = 3 2})$ & $\begin{array}{c}\text { Chronic pain } \\
(\mathbf{n}=34)\end{array}$ & $\mathbf{P}$ \\
\hline Stroop & & & \\
W card & $3(9.4)$ & $1(2.9)$ & 0.35 \\
C card & $1(3.1)$ & $0(0.0)$ & 0.49 \\
C/W card & $0(0.0)$ & $0(0.0)$ & - \\
TMT & & & \\
Part A & $0(0.0)$ & $2(5.9)$ & 0.49 \\
Part B & $0(0.0)$ & $4(11.8)$ & 0.11 \\
Bourdon completion time & $3(9.4)$ & $5(14.7)$ & 0.71 \\
Bourdon omissions & $1(3.1)$ & $3(8.8)$ & 0.61 \\
Zoo Map & & & 0.61 \\
Profile score 0 or 1 & $0(0.0)$ & $1(3.0)$ & \\
Profile score 2 & $10(31.3)$ & $11(33.3)$ & \\
Profile score 3 or 4 & $21(65.5)$ & $21(63.6)$ & \\
Total impaired tests & & & 0.23 \\
0 & $27(84.4)$ & $24(70.6)$ & \\
1 & $3(9.4)$ & $5(14.7)$ & \\
2 & $1(3.1)$ & $5(14.7)$ & \\
3 & $1(3.1)$ & $0(0.0)$ & \\
$>3$ & $0(0)$ & $0(0)$ & \\
\hline
\end{tabular}

Data represent the number of participants, $n$ (\%), who performed in the impaired range (-2 SD), with the exception of the Zoo Map profile and Total impaired tests scores, which represent the number (\%) of participants who obtained that score. $P$ values represent the outcome of $X^{2}$ tests to test for group differences. C Colour; C/W Colour/word; W Word; TMT Trail Making Test

$\left.P<0.05, \eta^{2}=0.08\right)$, and a marginally significant effect appeared with regard to the omissions made on the different lines of this test $\left(\mathrm{F}[1,63]=3.11, \mathrm{P}=0.08, \eta^{2}=0.05\right)$.

\section{Planning}

Nearly all participants obtained the maximum raw score on the second card (with the exception of two controls and two participants in the chronic pain group). The study, therefore, did not analyze the raw score of the second card but simply analyzed the raw score of the first card with an ANOVA. No significant effect for group was found $\left(\mathrm{F}[1,62]=0.18, \mathrm{P}=0.67, \eta^{2}=0.00\right)$. For the planning time, neither the effect of group $\left(F[1,61]=0.54, P=0.47, \eta^{2}=0.01\right)$ nor the interaction between group and planning time $\left(F[1,61]=0.01, P=0.91, \eta^{2}=0.00\right)$ was significant. The same pattern of results was also obtained for the completion time measures, where the main effect of group $(F[1,61]=0.03$, $\left.\mathrm{P}=0.86, \eta^{2}=0.00\right)$ and the interaction between group and completion time $\left(F[1,61]=0.99, P=0.32, \eta^{2}=0.02\right)$ did not reach significance.

Current pain intensity, pain duration and confounders

Current pain intensity ranged between $0 \mathrm{~mm}$ and $79 \mathrm{~mm}$ on a $0 \mathrm{~cm}$ to $10 \mathrm{~cm}$ scale. The correlations between the current pain intensities and the cognitive task scores (not including the raw score of the second, structured card of the Zoo Map) were all nonsignificant. In addition, the cognitive task scores did not correlate significantly with pain duration, number of hours lying awake, depressive symptoms or the PCS scores. Finally, use of opioids was not associated with performance on the attention and executive function tests.

Effort to complete tasks

For the Stroop and TMT, age- and education-corrected normative data were available. For the Zoo Map test, no normative data were available but performance on this test could be converted to a profile score. This profile score ranged between 0 and 4 . For the current analysis, a score of 0 or 1 was defined as impaired, a score of 2 as 
borderline intact, and a score of 3 or 4 as intact. Finally, no normative data were available for adults for the Bourdon-Vos test either. Previously published results of controls (31) were used to determine potential below average performance in the participants.

Because few participants demonstrated impaired performance on one or more tests, Fisher's exact testing was used to examine potential differences between these frequencies, except for the Zoo Map where three outcome options were tested (Table 3). In addition, the total number of tasks on which the participants performed in the impaired range were examined. No group differences were found on any of these outcome measures. Additional Kruskal-Wallis testing, in which the total number of tasks on which performance was impaired were defined as none $(n=51)$, one $(n=8)$ and two or more $(n=7)$, revealed that an increase in the number of impaired tasks was associated with higher age $\left(\chi^{2}[2]=8.16, \mathrm{P}<0.05\right)$ and lower estimated IQ $\left(\chi^{2}[2]=11.85, \mathrm{P}<0.01\right)$.

\section{DISCUSSION}

The present study investigated executive and attentional functions in chronic pain while taking reductions in psychomotor speed into account. The findings demonstrate that participants with chronic pain perform worse than controls on tests of mental flexibility and sustained attention, but not on inhibition or planning ability. With regard to the mental flexibility task and the completion time of the sustained attention test, we did not find evidence that performance of the participants with chronic pain was disproportionately affected with increasing task load. This indicates that the decline in performance on these tasks is more likely the net result of psychomotor slowing. Notably, however, the results on the sustained attention task indicate that chronic pain patients have decreased attentional functioning. More omissions on the second part of the sustained attention task were made compared with the first part, whereas the opposite pattern was observed in the control group. Also, the chronic pain group revealed increased fluctuations in attention, as indicated by an increased variability in completion time and omissions across the different lines of the task. To summarize, several executive and attentional functions (ie, mental flexibility, planning and inhibition) appear to be largely intact in chronic pain except for a specific decline in the ability to sustain attention.

In the present study, we found intact inhibition, which is in agreement with previous studies on selective attention or inhibition in this patient group $(11,12)$. For the planning test, little is known about the potential disruptive effects of chronic pain on task performance. To our knowledge, we are the first to examine this function in chronic pain and show that planning is still intact in this group. Our study findings are further in line with previous studies that demonstrated diminished performance on sustained attention and mental flexibility tasks in chronic pain patients. Sjøgren et al (5) examined neuropsychological functioning of chronic pain patients on a sustained attentional performance reaction time test in which patients had to respond as fast as possible to auditory signals delivered over a $10 \mathrm{~min}$ period. The authors found longer reaction times for patients compared with controls for this test. Interestingly, they also found lower performance of the chronic pain patients on a finger tapping task, measuring motor speed. It thus remains unclear from these findings whether sustained attention was affected independently of diminished speed or whether the slower reaction times on the auditory reaction time test were due to impairments in speed in this patient group. The same holds for the study by Wiener et al (45). These authors demonstrated decreased performance on part B of the TMT in older chronic pain patients, but performance on a test for fine motor performance (the Grooved Pegboard) was also diminished in this patient group. Also in that study it remained unclear whether mental flexibility was affected or whether psychomotor slowing could explain the findings. The present study is the first to indicate that slowing on a task of mental flexibility may be due to reductions in basic cognitive functions, whereas difficulties in sustaining attention may be independent of these processes.
The mechanisms for the decline in attention and executive function in chronic pain patients remain largely unclear. Several different hypotheses have been postulated to explain reduced cognitive, and in particular attentional, functions in chronic pain patients. It has been argued that patients have an attentional bias toward painful sensations which may cause distraction from other stimuli. In a recent study, rats with monoarthritis caused by complete Freund's adjuvant showed a marked decline in a sustained attention task (five-choice serial reaction time task) (46). After pain was induced, rats were less accurate and made more omissions on this task. Interestingly, this decline in performance was not altered by transient analgesic drug administration, indicating that distraction due to pain is probably not the main cause of attentional deficits in chronic pain.

Another hypothesis is that attention and pain share common resources (47). The experience of pain may reduce the capacity to attend to another stimulus because it captures attentional resources itself. In this perspective, it is expected that with increasing task demands cognitive task performance decreases disproportionally in chronic pain patients. Our results are not completely in line with this view because such a specific pattern of results was not observed for three different executive function tests. An alternative perspective proposes that perhaps attentional capacity is not impaired in chronic pain, but chronic pain patients have the tendency to allocate attention differently $(48,49)$. An attentional bias toward stimuli, especially pain, has been described by the hypervigilance perspective. Recent data suggest that allocation of attention is different in chronic pain patients, and not necessarily only when pain-related information is involved (49). It seems reasonable to assume that the allocation of attention is particularly sensitive to long durations over time. Our present finding that participants with chronic pain have a specific difficulty in sustaining attention might therefore potentially reflect an underlying problem in the allocation of attention.

Increasing pain severity has been previously found to be associated with decreased cognitive task performance $(3,45,50)$. For example, Grisart and Plaghki (4) found that selective attention or inhibition, as assessed with the Stroop Colour Word task, was affected in chronic pain patients, but only in patients with pain of high intensity with a visual analogue scale score of 60 or more. In the present study, no significant association was observed between pain severity and performance on the neuropsychological tasks. Potentially, the level of pain intensity in our chronic pain sample was not severe enough to replicate the previously observed associations between pain intensity and cognitive task performance. Future studies on the pattern of attentional task performance in chronic pain patients could consider including patients with higher pain intensity levels. It is possible that the specific decline in task performance with increasing task demands is present in chronic pain patients with high pain intensity levels.

One potential limitation of our study is that we included a heterogeneous sample of participants with chronic pain. The extent to which this explains the absence of a specific executive deficit in our sample is unclear. However, in a previous study with the same heterogeneous patient sample, we were able to find significantly lower performance on multiple memory tests (50). Nevertheless, the current results should be replicated in more homogeneous patient samples.

Also, the attention and executive function domains cover multiple aspects of cognition, some of which were not addressed in the current study. For example, working memory and set shifting have also been denoted as aspects of executive function (6), while others have tried to differentiate between alerting, orienting and executive attention (51). Only several indices of attention and executive function were examined in the present study; future studies are therefore needed to obtain a more complete assessment of the executive and attention domains.

A final point of consideration concerns the high variability in performance on some of the tests (eg, the TMT-B and the Zoo Map test) in the chronic pain group. This could possibly reflect low validity of these tests, but an increase in variances in test performance has often been reported in different clinical groups $(52,53)$. The 
Behavioural Assessment of the Dysexecutive Syndrome, including the Zoo Map test, was specifically designed as an ecologically valid test of planning. Because performance on this test did not differ between the chronic pain group and the control group, it is unlikely that low validity of the neuropsychological tests explains the entire pattern of findings.

\section{SUMMARY}

Executive and attention functions appear to be largely intact in chronic pain, with the exception of a significant decline in attentional resources on sustained attentional task performance. The lower performance on mental flexibility is presumably due to more basic cognitive processes such as psychomotor slowing. No impairment in inhibition or planning ability was found. This study provides new insights into executive function and attention deficits in chronic pain patients.

\section{REFERENCES}

1. Nicholson K, Martelli MF, Zasler ND. Does pain confound interpretation of neuropsychological test results? NeuroRehabilitation 2001;16:225-30.

2. Moriarty $\mathrm{O}, \mathrm{McGuire} \mathrm{BE}$, Finn DP. The effect of pain on cognitive function: a review of clinical and preclinical research. Prog Neurobiol 2011;93:385-404.

3. Eccleston C. Chronic pain and distraction: An experimental investigation into the role of sustained and shifting attention in the processing of chronic persistent pain. Behav Res Ther 1995;33:391-405.

4. Grisart JM, Plaghki LH. Impaired selective attention in chronic pain patients. Eur J Pain 1999;3:325-33.

5. Sjøgren P, Christrup LL, Petersen MA, Højsted J. Neuropsychological assessment of chronic non-malignant pain patients treated in a multidisciplinary pain centre. Eur J Pain 2005;9:453-62.

6. Lezak MD, Howieson DB, Loring DW. Neuropsychological Assessment. New York: Oxford University Press, 2004.

7. Sarter M, Givens B, Bruno JP. The cognitive neuroscience of sustained attention: Where top-down meets bottom-up. Brain Res Rev 2001;35:146-60.

8. Bowie CR, Harvey PD. Administration and interpretation of the Trail Making Test. Nat Protoc 2006;1:2277-81.

9. Kortte KB, Horner MD, Windham WK. The trail making test, part B: Cognitive flexibility or ability to maintain set? Appl Neuropsychol 2002;9:106-9.

10. Mead LA, Mayer AR, Bobholz JA, et al. Neural basis of the Stroop interference task: Response competition or selective attention? J Int Neuropsychol Soc 2002;8:735-42.

11. Apkarian AV, Sosa Y, Krauss BR, et al. Chronic pain patients are impaired on an emotional decision-making task. Pain 2004;108:129-36.

12. Suhr JA. Neuropsychological impairment in fibromyalgia: Relation to depression, fatigue, and pain. J Psychosom Res 2003;55:321-9.

13. Guéz M, Brännström R, Nyberg L, Toolanen G, Hildingsson C. Neuropsychological functioning and MMPI-2 profiles in chronic neck pain: A comparison of whiplash and non-traumatic groups. J Clin Exp Neuropsychol 2005;27:151-63.

14. Veldhuijzen DS, van Wijck AJ, Wille F, et al. Effect of chronic nonmalignant pain on highway driving performance. Pain 2006;122:28-35.

15. Karp JF, Reynolds CF 3rd, Butters MA, et al. The relationship between pain and mental flexibility in older adult pain clinic patients. Pain Med 2006;7:444-52.

16. Verdelho-Garcia A, López-Torrecillas F, Calandre EP, Delgado-Rodríguez A, Bechara A. Executive function and decision-making in women with fibromyalgia. Arch Clin Neuropsychol 2009;24:113-22.

17. Sjøgren P, Thomsen AB, Olsen AK. Impaired neuropsychological performance in chronic nonmalignant pain patients receiving long-term oral opioid therapy. J Pain Symptom Manage 2000;19:100-8.

18. Hart RP, Martelli MF, Zasler ND. Chronic pain and neuropsychological functioning. Neuropsychol Rev 2000;10:131-49.

19. Crowe SF The differential contribution of mental tracking, cognitive flexibility, visual search, and motor speed to performance on parts A and B of the Trail Making Test. J Clin Psychol 1998;54:585-91.

20. Kertzman S, Reznik I, Hornik-Lurie T, Weizman A, Kotler M, Amital D. Stroop performance in major depression: Selective attention impairment or psychomotor slowness? J Affect Disord 2010;122:167-7.

21. Oosterman JM, Vogels RL, Van Harten B, et al. Assessing mental flexibility: Neuroanatomical and neuropsychological correlates of the Trail Making Test in elderly people. Clin Neuropsychol 2010;24:203-19.

22. Stuss DT, Floden D, Alexander MP, Levine B, Katz D. Stroop performance in focal lesion patients: Dissociation of processes and frontal lobe lesion location. Neuropsychologia 2001;39:771-86.

23. Van der Kloot WA, Oostendorp RA, Van der Meij J, van den Heuvel J. De Nederlandse versie van "McGill pain questionnaire": Een betrouwbare pijnvragenlijst. (The Dutch version of the McGill pain questionnaire: A reliable pain questionnaire). Ned Tijdschr Geneeskd 1995;139:669-73.

24. Schmand B, Bakker D, Saan R, Louman J. De Nederlandse Leestest voor Volwassenen (NLV): Een maat voor het premorbide intelligentieniveau (The Dutch Adult Reading Test (DART): A measure of premorbid intelligence). Tijdschr Gerontol Geriatr 1991;22:15-9.

25. Folstein MF, Folstein SE, McHugh PR. "Mini-mental state". A practical method for grading the cognitive state of patients for the clinician. J Psychiatr Res 1975;12:189-98.

26. Vos PG. Bourdon Vos test handleiding (Bourdon vos test manual). Lisse: Swets \& Zeitlinger BV, 1998.

27. Vos PJ, Folgering HT, van Herwaarden CL. Visual attention in patients with chronic obstructive pulmonary disease. Biol Psychol 1995;41:295-305.

28. Bruggeman C, Eling P, Jansen R. Een nieuwe maat voor de diagnostiek van aandachtsstoornissen (A new measure of attentional deficits). Ned Tijschr Psychol;45:205-13.

29. Wilson BA, Alderman N, Burgess PW, Emslie H, Evans JJ. Behavioural assessment of the dysexecutive syndrome. Bury St Edmunds: Thames Valley Test Company, 1996.

30. Sullivan MJL, Bishop S, Pivik J. Pain Catastrophizing Scale: Development and validation. Psychol Assess 1995;7:524-32.

31. Crombez G, Vlaeyen JWS. The Pain Catastrophizing Scale. Unpublished Dutch/Flemish translation, 1996.

32. Van Damme S, Crombez G, Vlaeyen JWS, et al. De Pain Catastrophizing Scale: Psychometrische karakteristieken en normering (The Pain Catastrophizing Scale: Psychometric characteristics and norms). Gedragstherapie 2000;33:209-20.

33. Crombez G, Eccleston C, Van den Broeck A, Van Houdenhove B, Goubert L. The effects of catastrophic thinking about pain on attentional interference by pain: No mediation of negative affectivity in healthy volunteers and in patients with low back pain. Pain Res Manage 2002;7:31-9.

34. Vancleef LM, Peters ML. Pain catastrophizing, but not injury/illness sensitivity or anxiety sensitivity, enhances attentional interference by pain. J Pain 2006;7:23-30.

35. Yesavage JA, Brink TL, Rose T, et al. Development and validation of a geriatric screening scale: A preliminary report. J Psychiatr Res 1982-1983;17:37-49.

36. Ferraro FR, Chelminski I. Preliminary normative data on the Geriatric Depression Scale-Short Form (GDS-SF) in a young adult sample. J Clin Psychol 1996;52:443-7.

37. Rule BG, Harvey HZ, Dobbs AR. Reliability of GDS in adult population. Clin Gerontol 1989;9:37-43.

38. Blankstein U, Chen J, Diamant NE, Davis KD. Altered brain structure in irritable bowel syndrome: Potential contributions of pre-existing and disease-driven factors. Gastroenterology 2010;138:1783-9.

39. Moayedi M, Weissman-Fogel I, Crawley AP, et al. Contribution of chronic pain and neuroticism to abnormal forebrain gray matter in patients with temporomandibular disorder. Neuroimage 2011;55:277-86.

40. Blom G. Statistical Estimates and Transformed Beta Variables. New York: John Wiley and Sons, 1958.

41. Greve KW, Ord JS, Bianchini KJ, Curtis KL. Prevalence of malingering in patients with chronic pain referred for psychologic evaluation in a medico-legal context. Arch Phys Med Rehabil 2009;90:1117-26. 
42. Mittenberg W, Patton C, Canyock EM, Condit DC. Base rates of malingering and symptom exaggeration. J Clin Exp Neuropsychol 2002;24:1094-102.

43. Gervais RO, Russell AS, Green P, Allen LM III, Ferrari R, Pieschl SD. Effort testing in patients with fibromyalgia and disability incentives. J Rheumatol 2001;28:1892-9.

44. Schmand B, Lindeboom J, Schagen S, Heijt R, Koene T, Hamburger HL. Cognitive complaints in patients after whiplash injury: The impact of malingering. J Neurol Neurosurg Psychiatry 1998;64:339-43.

45. Weiner DK, Rudy TE, Morrow L, Slaboda J, Lieber S. The relationship between pain, neuropsychological performance, and physical function in community-dwelling older adults with chronic low back pain. Pain Med 2006;7:60-70.

46. Pais-Vieira M, Lima D, Galhardo V. Sustained attention deficits in rats with chronic inflammatory pain. Neurosci Lett 2009;463:98-102.

47. Eccleston C, Crombez G. Pain demands attention: A cognitive-affective model of the interruptive function of pain. Psychol Bul 1999;125:356-66.
48. Crombez G, Van Damme S, Eccleston C. Hypervigilance to pain: An experimental and clinical analysis. Pain 2005;116:4-7.

49. Veldhuijzen DS, Kenemans JL, Van Wijck AJ, Olivier B, Kalkman CJ, Volkerts ER. Processing capacity in chronic pain patients: A visual event-related potentials study. Pain 2006;121:60-8.

50. Oosterman JM, Derksen LC, van Wijck AJ, Veldhuijzen DS, Kessels RPC. Memory functions in chronic pain: Examining contributions of attention and age to test performance. Clin J Pain 2011;27:70-5.

51. Posner MI, Rothbart MK. Research on attention networks as a model for the integration of psychological science. Annu Rev Psychol 2007;58:1-23.

52. Rumsey JM, Hamburger SD. Neuropsychological divergence of high-level autism and severe dyslexia. J Autism Dev Disord 1990;20:155-68.

53. Sano M, Raman R, Emond J, et al. Adding delayed recall to the Alzheimer Disease Assessment Scale is useful in studies of mild cognitive impairment but not Alzheimer disease. Alzheimer Dis Assoc Disord 2011;25:122-7. 


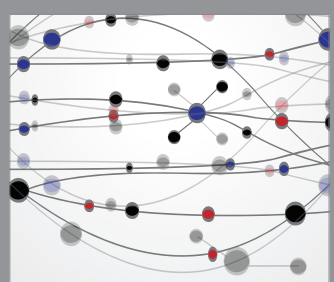

The Scientific World Journal
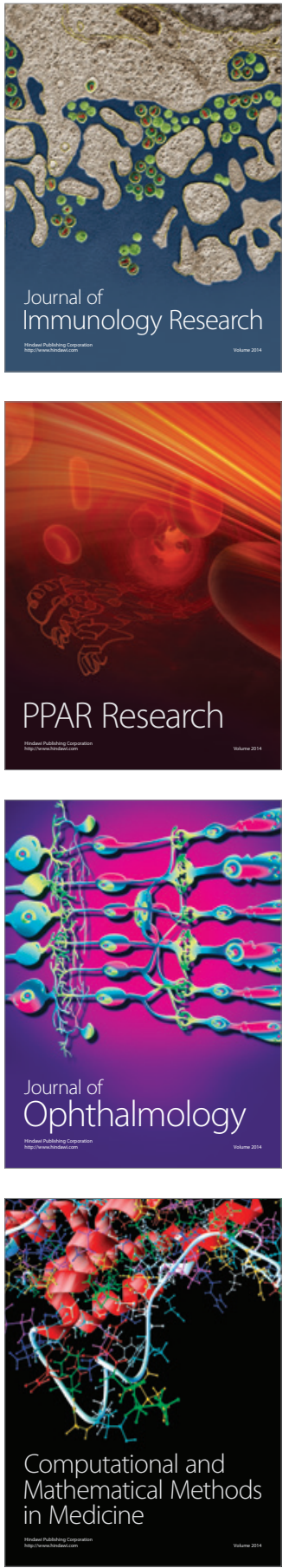

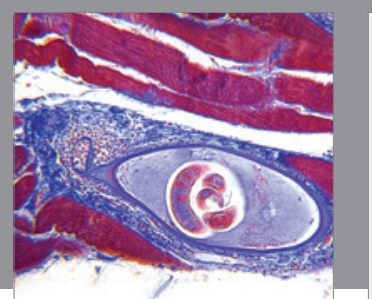

Gastroenterology Research and Practice

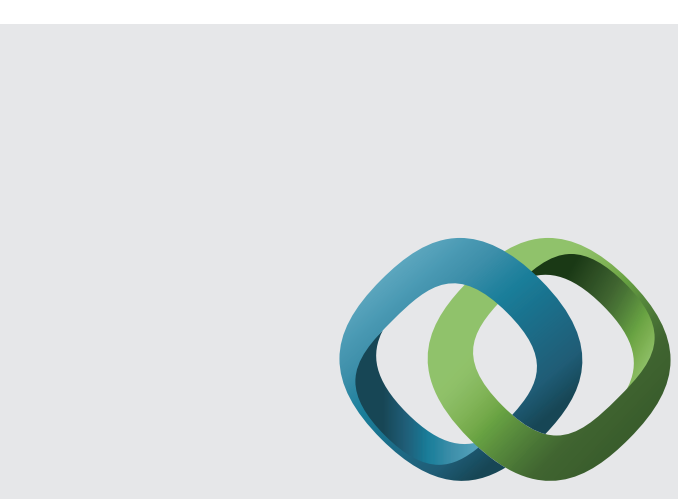

\section{Hindawi}

Submit your manuscripts at

http://www.hindawi.com
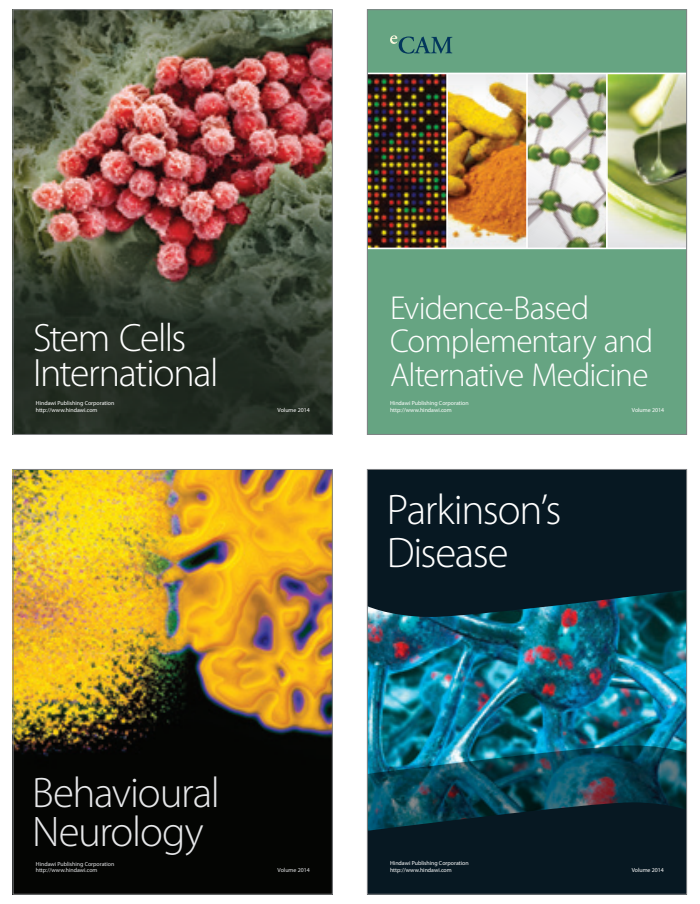
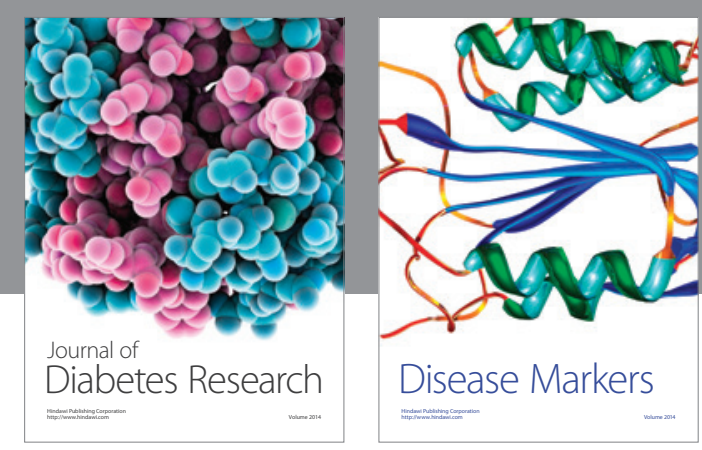

Disease Markers
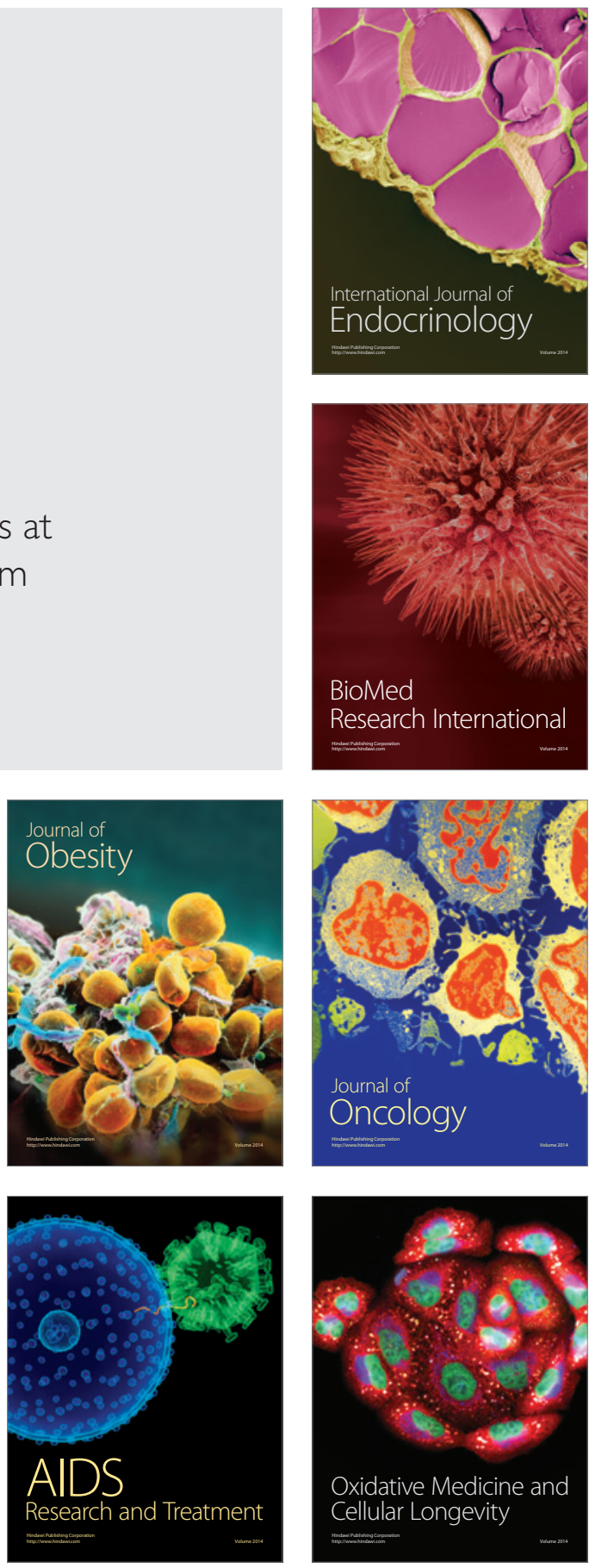